\title{
A Corpus Linguistic Analysis of Public Tumblr Blog Posts on Non-Suicidal Self-Injury
}

\author{
A Preprint \\ Mandy M. Greaves ${ }^{1}$ \\ Cass Dykeman \\ Fresno State University \\ Oregon State University \\ Counselor Ed. and Rehab. \\ Counseling Acad. Unit \\ 5005 N Maple Ave, MS ED1 \\ 104 Furman Hall \\ Fresno, CA 93740-8025 \\ Corvallis, OR 97331
}

\footnotetext{
${ }^{1}$ Correspondence concerning this preprint should be addressed to Mandy M. Greaves at mgreaves@mail.fresnostate.edu
} 


\begin{abstract}
Rates of non-suicidal self-injury (NSSI) have steadily risen among adolescents and young adults. This study collected pro-NSSI public blog posts from Tumblr and analyzed the content linguistically using LIWC software, examining the NSSI-specific words, the linguistics properties and the psychological linguistic properties. The results align with similar studies conducted on the language markers of mental health. For NSSI specific word categories, the methods of engaging in NSSI was the most frequently used in the Tumblr blogs. This aligns with literature about the need for people to express their emotional pain to others who may understand. The linguistic properties demonstrated some unique results that can be best explained by the numbing feeling that is found in individuals who utilize NSSI and their tendency to avoid expressing painful experiences in a manner that would increase their vulnerability. The psychological properties of these public Tumblr posts were revealed through the dominantly negative emotional tone of the writing, which is also indicative of anyone struggling with severe mental illness. These findings suggest that treatment which specializes in shame and increasing self-compassion, such as Compassion Focused Therapy, would be more beneficial to these individuals who struggle with pain, shame and emotional distress than current treatment programs.
\end{abstract}

Keywords: NSSI, LIWC, linguistic analysis, mental health, selfinjury 


\section{A Corpus Linguistic Analysis of Public Tumblr Blog Posts on Non-Suicidal Self-Injury}

Adolescents and emerging adults live in a social media world and as mental health professionals we need to meet them where they are at. The rise of social media has dramatically transformed how information is conveyed and received; now, unlike a decade ago, information can be delivered within seconds of an event. Additionally, non-suicidal self-injury (NSSI) and other mental illnesses have been on the rise, especially among adolescents. The combination of NSSI and social media has created confusion about whether social media is more beneficial or more harmful for adolescents. Since Tumblr, a microblogging site, has attempted to eliminate pro-NSSI posts, by banning all pro-NSSI and other forms of selfinjury such as pro-eating disorder blog pages, studies have been conducted to learn whether or not censorship can help reduce the spread of pro-NSSI and pro-eating disorder information via social media. Unsurprisingly, for those of us who have teenagers or work with them professionally, these studies have demonstrated that adolescents find a way around the censorship and continue to post pro-NSSI and pro-eating disorder information (Eveleth, 2013).

When the blogging phenomenon began, they were typically journals for other people to read and connect to. Over the years, blogs have been transformed; while they are still a form of self-expression and way to share one's interests and passions, they have become platforms for sharing knowledge on a particular topic, practicing writing skills, earning exposure and building a network (Dekmezian, 2015). New, website-based social media platforms now cater to those who want to have blogs on various topics. The most widely known and used website is Twitter, a micro-blog site that provides information in bite-sized bits called "tweets." Other sites, like Tumblr, provide a greater variety of blogging options, including a wide range of topics for blogging and commenting on. While Tumblr has tried to ban pro-NSSI blogs and pro-eating disorder blogs, little has made an impact on the actual posting of these blogs.

Social media and blogs have achieved their highest use rate ever (Smith \& Anderson, 2018), and they have become a place where NSSI is frequently discussed. There are many reasons why people use self-injury 
and why they post about it on personal social media pages and blogs. One study conducted by Harris and Roberts (2013) explored the reasons why adolescents and young adults go to social media and blog sites to read and post about their self-injury. The researchers discovered a number of reasons for individuals that engage in NSSI to engage with these social media websites; they categorized these into five broad themes: (1) "help and support", (2) "isolation reduction and community engagement", (3) "distraction and expression", (4) "help others" and (5) "triggering material/tips." Harris and Roberts (2013) discovered that self-injury is a very socially isolating behavior since it is performed by one's self. Other researchers, like Gilbert (2010), add that there is a level of shame that is attached to engaging in self-destructive behaviors. Participants in the Harris and Roberts (2013) study emphasized that these pro-NSSI websites and blogs provide a community of people who understand their experiences; it seems as though these websites and blogposts have both positive and negative aspects. While the studies of Harris and Roberts and others may provide a better understanding about why people post on NSSI blogs and social media communities, there is still little information about the language in which they use and how their use of language describing their experiences can clue mental health therapists into the person's inner workings and thoughts.

Despite how young people are clearly heavily influenced by social media, there is little knowledge about the persuasive and psychological processes occurring within the pro-NSSI space on the internet. There is also very little knowledge about how these individuals talk about their NSSI with others. Without such knowledge, the nature of what mental health interventions can be most useful to this population remains obscure.

After reviewing the literature on both non-suicidal self-injury and blog use, it was clear that there are six important issues to consider in the study: (1) providing a definition of non-lethal self-injury, (2) understanding that NSSI usually begins in adolescence, (3) examining proNSSI posts in blogs, especially on Tumblr, (4) the influence of social media and blogs on people's decisions, (5) mental health and the use of the internet, and (6) exploring the use of LIWC as a new method of 
understanding language online. Finally, the research questions will be detailed.

An examination of relevant scientific literature reveals that there are multiple definitions of and explanations for NSSI. Favazza (1998) is one of the most widely cited resources for self-harm/self-mutilation. According to Google Scholar (2015), this reference has been cited 688 times in the professional literature. Favazza defines "self-mutilation (SM), [as] the deliberate, non-suicidal destruction of one's own body tissue" (p. 260). He concludes by stating, "SM includes compulsive acts such as trichotillomania and skin picking and such episodic acts as skin-cutting and burning" (p. 259). Skegg's definition of self-harm first appeared in the literature in 2005 and has also been cited widely (448 times; Google Scholar, 2015); Skegg's definition expanded Favazza's definition of selfmutilation/self-harm to include other behaviors, namely overdosing. Furthermore, Skegg argues that self-harm takes place on a continuum of behaviors; all of which are "deliberate" and "self-wounding" behaviors (p. 1471). The difference between NSSI and suicidal behavior is the individual's intent; individuals engaged in NSSI typically aim to cope (non-fatally) with their disturbing feelings, while suicidal behavior aims to end all feelings through the loss of life (Jarvi, Jackson, Swenson \& Crawford, 2013).

There are few precise numbers and statistics describing NSSI rates, in part because it is difficult to collect accurate data. of the, the classification system in hospitals do not distinguish between NSSI behaviors and suicidal behavior. In addition to the flawed classification system, not everybody will report their NSSI behaviors to someone, especially a professional. Researchers have estimated that by the age of 14 or 15, approximately one in 12 adolescents engage in NSSI behaviors; this is estimated to be about six to ten percent of all teenagers (Allen, 2011). Newer statistics reveal that about $90 \%$ of people who engage in NSSI began during their teen or pre-adolescent years (Healthyplace.com, 2016). These statistics reveal that more research needs to be done to better help adolescents and pre-adolescents before the NSSI behavior becomes worse. 
As micro-blogs like Twitter and Tumblr have increased in popularity and frequency of use, they have become the new way that people receive information ( $\mathrm{Li}$ and $\mathrm{Du} 2014$ ). Li and Du noted the difference between a micro-blog and blog in their study, which is that micro-blogs are mostly used as a channel to express one's opinion, which often skews the information being received by so many. Individuals who engage in NSSI who use micro-blogs often, problematically, influence others either to begin or to continue with the viewer's NSSI. A study by Chancellor (2016) noted that the use of visual images in social media, especially Tumblr and Instagram, encourages the continuation of distorted thoughts and behaviors. As social media becomes more popular and the number of pro-NSSI posts increases, this tendency to influence others with opinions and images that continue distorted thoughts and behaviors could potentially cause other vulnerable individuals to either begin using NSSI behaviors to cope with negative feelings or to continue and escalate their current NSSI behaviors.

Social media can influence people's thoughts and behaviors, such as consumer decisions or personal feelings about themselves. This is known as social contagion, which can be loosely defined as "behaviors [that are] spread throughout a community" (Aalai, 2018, para. 3). A prominent example of social contagion is a positive association with exposure to suicidal behavior and peer suicide attempts (Jarvi et al., 2013). In many communities, we see a cluster of adolescent suicides that occur within weeks of each other (Mueller, 2017). This phenomenon of social contagion is supported the theory by Alfred Bandura's social learning theory (1977), which posits that individuals learn through imitating a model. For example, in terms of delinquent behaviors, adolescents appear to be more susceptible to peer influence and social contagion. Studies have found that adolescents are especially susceptible to social contagion because they have difficulties with self-regulation and thus impulse control is minimal (Jarvi et al., 2013).

As social media has increasingly impacted peoples' lives, it has become an important topic for study in mental health circles. Research has been divided on the topic of whether social media is helpful or harmful to individual's mental health. While adolescents and young adults have reported that social media gives them a community of people struggling with similar issues and as a source of support (O'Reilly et al., 2018), there 
is much more evidence to support the idea that social media is more damaging to adolescents' and young adult's mental health than helpful. Studies have demonstrated that social media potentially leads to depression and suicidal behavior (Mars et al., 2015; O'Reilly et al., 2018). For individuals who engage in NSSI, there are many positive resources and websites to help someone cope with negative feelings and on how to eliminate NSSI. The dark side, however, is that there are also websites and blogs that promote and encourage NSSI by providing tips on how to self-harm and how to hide self-harm. While this controversy continues, there is little known about the impact of social media on NSSI behavior and still less information about the language that is used to describe NSSI.

As social media emerged and grew in popularity, researchers became interested in how people use language in social media posts and what mental health professionals can learn from their language. As early as 2013, Choudhury, Counts, and Horvitz examined the language in social media posts to identify people who may be suffering with post-partum depression. They noted that language can provide useful "psychological markers" that give useful information into an individual's inner workings. More recently, researchers have started to make an effort to understand the language of self-harm.

The most frequently used method for studying language is corpus linguistics. First, the researcher constructs a corpus using large amounts of data drawn from online social media, which is subsequently inputted into software for analysis. The software the completes a deeper and more nuanced in-depth analysis than what people are capable of doing (McGlashan, 2018). The Linguistic Inquiry and Word Count (LIWC; Pennebaker et al., 2007) software is the most frequently used tool in corpus linguistics related scholarship; the LIWC analyzes and calculates aspects of language including the use of emotional words, social word use, self-referencing, drives and pronoun use (Adrian et al., 2011). Carefully examining these aspects of language has the potential to provide mental health professionals with further insight into the individual's experience and environment.

Given the promise and demonstrated usefulness of the corpus linguistics method of studying textual content, three research questions 
were designed to guide this study. The first research question was: What is the NSSI specific content word use of the individuals making posts? The NSSI specific content word use categories were: Methods of NSSI, CuttingSpecific Terms, NSSI Terms, Instruments Used, Reasons for NSSI, and Hidden Hashtag Terms. The second research question was: What is the pattern of use of linguistics processes of the individuals making posts compared to the pattern that appears in blogs overall? The linguistics process categories were: $1^{\text {st }}$ person singular, $1^{\text {st }}$ person plural, $3^{\text {rd }}$ person singular, and $3^{\text {rd }}$ person plural. The third research question was: What is the pattern of use of psychological processes of the individuals making posts compared to the pattern that appears in blogs overall? The psychological process categories were: emotional tone, negative emotions, anxiety, anger, sadness and risk focus.

\section{Method}

\section{Design}

This study employed a synchronic corpus linguistic design for exploring public Tumblr posts on NSSI (Weisser, 2017). The Linguistic Inquiry and Word Count (LIWC) was used to analyze the Tumblr posts containing pro-NSSI. The variables were the following linguistic categories: $1^{\text {st }}$ person singular pronouns, $3^{\text {rd }}$ person singular pronouns, $1^{\text {st }}$ person plural pronouns, $3^{\text {rd }}$ person plural pronouns, emotional tone, negative emotion, anxiety, anger, sadness and risk. It also was used to analyze another set of categories that were NSSI-specific: methods of NSSI, cutting-specific terms, NSSI terms, instruments use, reasons for NSSI, and hidden hashtag terms. The sample was compiled from Tumblr during a year's worth of data ranging from January 1, 2017 to December 31, 2017. The sample was compared to individuals who make Tumblr posts from national norms for social media posts.

\section{Corpus}

The researchers used Tumblr's API system to collect public posts that occurred between January 1, 2017 and December 31, 2017 to construct the corpus. The API was instructed to scrape posts that: (a) used monolingual English and (b) were comprised of the list of NSSI terms compiled by the researchers (list available from first author). The API 
was instructed to eliminate the following while collecting the text: user names, URLs, hashtags, location of the posts, posts from outside of the United States, photographs and foreign languages. As a result of these API instructions, over two thousand Tumblr posts were collected and then cleaned. This cleaning included the following: (a) abbreviations were spelled out, (b) UK English word converted to US English, and (c) lexical variants, textese, and out-of-vocabulary were transformed by lexical normalization.

\section{Measures}

Greaves NSSI Linguistic Scales (GNLS). These six scales contain words related to the following aspects of NSSI behavior: (1) methods (e.g., erasing), (2) cutting-specific terms (e.g., cut), (3) terms (e.g., nonsuicidal), (4) instruments (e.g., blade), (5) reasons (e.g., anxiety), and (6) hidden hashtag terms (e.g., selfharmmmm). The score for each scale is reported as the percentage of all words in the corpus.

Linguistic Inquiry and Word Count (LIWC). This instrument contains scales covering a wide variety of linguistic and psychological processes. The linguistic scales selected for this study included those known to be associated with a person's level of social relatedness. These scales were (a) $1^{\text {st }}$ person singular pronoun (e.g., I), (b) $3^{\text {rd }}$ person singular pronoun (e.g., he), (c) $1^{\text {st }}$ person plural pronoun (e.g., we), and (d) $3^{\text {rd }}$ person plural pronoun (e.g., they). The LIWC psychological scales selected were those ones that contained processes noted in NSSI studies. The scales were (a) emotional tone, (b) negative, (c) emotion, (d) anxiety, (e) anger, (f) sadness, and (g) risk. Except for emotional tone, the score for each scale is reported as the percentage of all words in the corpus. Emotional tone is reported on a scale of 0 to 100 with scores over 50 suggesting a warmer tone. Pennebaker, Boyd, Jordan, and Blackburn (2015) report adequate reliability and validity for the LIWC scales.

\section{Data Analysis}

For the first research question, the raw count for each word in each category will be calculated and the percentage of all words for each NSSIspecific category will be reported. In terms of the second and third 
research questions, the following will be reported for all categories except for emotional tone: (a) percentage of all words, (b) log likelihood statistic of the comparison of the NSSI corpus to blog general norms, and (c) log ratio of the comparison of the NSSI corpus to blog general norms. The log likelihood analysis requires raw scores; raw scores were calculated by multiplying the percentage of all words and the size of the corpus. The log likelihood formula used was from Cressie and Read (1989) as cited in Rayson and Garside (2010). The log ratio is a measure of effect size (Hardie, 2014). As Hardie notes, a log ratio of 1 means a word is twice as common in a corpus than a comparison corpus. The score for emotional tone is based upon a standard score rather than a raw score. As such, a one sample $z$ test of proportion was used to analyze this category rather than the log likelihood test. All analyses were conducted using Excel. Given the small number of analyses conducted, the standard .05 alpha level was retained.

\section{Results}

In the analysis of the first research question, the most frequently used NSSI-specific category was Reasons for NSSI. The percentage of all words were as follows: Methods of NSSI (25.77\%), Cutting-Specific Terms (18.67\%), NSSI Terms (15.23\%), Instruments Used (3.16\%), Reasons for NSSI (0\%), and Hidden Hashtag Terms (0\%). A list of the raw counts for the words or word stems in all categories can be found in Table 1. In terms of the second research question, the linguistic process category that differed most from the general blog norms was first person plural $(L L=$ 18.59). The effect size for this category was a $\log$ ratio of -1.34. Except for the emotional tone, a list of the results of all the categories can be found

in Table 2. In terms of emotional tone, the one sample $z$ test of proportion was significant $(z=-6.727, p<.05)$. In terms of the third research question, the psychological process category that differed most from the general blog norms was negative emotion $(L L=8.80)$. The effect size for this category was a log ratio of 0.50 .

\section{Discussion}

In this study, which examined the language used in pro-NSSI blogs on Tumblr, researchers examined whether there were differences in the use 
of language in pro-NSSI blogs when they were compared to blogs overall. Specifically, it focused on addressing the following questions about the presence and use of NSSI-specific language in the corpus: What is the NSSI specific content word use of the individuals making posts? What is the pattern of use of linguistics processes of the individuals making posts? What is the pattern of use of psychological processes of the individuals making posts? Next, results are presented and discussed. Toward the end of the section, limitations and implications of the findings are presented.

In answering the first research question, the researchers sought to understand the specific NSSI words that were used in these blog posts and found that the most frequently used words in pro-NSSI blog posts were the methods that individuals use to engage in NSSI. In this category, the most frequently used words were cut, erase and break. One explanation for the high frequency of these words is the most common method used to engage in NSSI is cutting.

While cutting one's skin is not the only method of self-injury, it is likely one of the most common ones. It is evident in the corpus that these individuals cut themselves in private and when they are in the public domains. It appears that cutting is one of the easiest behaviors to selfinjure without people taking notice. It is becoming evident in research that there is a difference in the occurrence of cutting and other methods of NSSI. Studies have found that cutting is the most common method of NSSI and least common among hospital presentations (Arensman et al., 2013). There also appears to be a difference in the gender distribution among methods to engage in NSSI. Cutting is one of the methods that demonstrates a more even gender distribution when compared to other methods such as intentional overdose (Arensman et al., 2013).

Words like cut, erase and break evokes strong feelings of distress and pain. These words may appear with a high frequency because individuals engaged in NSSI may be seeking coping strategies for the intense emotional pain they feel. Skegg (2005) noted that most people who engage in NSSI are attempting to relieve their distress, to seek help, to cope with their feelings and to gain a sense of control. Williams (2000) theorized that NSSI is more of a cry of pain than a cry for help. From what we understand in the literature, individuals who engage in NSSI feel 
intense emotional and psychological distress and pain. It makes sense that given the intense feelings and pain that these individuals experience daily, that those would be the most commonly used words while they are describing their experiences. While both reasons are plausible in understanding the specific NSSI word use, a more likely explanation is the common use of the method of cutting to engage in NSSI.

The second research question concerns the linguistic patterns in pro-NSSI blogs. The study data demonstrates that the use of the firstperson plural was the most frequent and statistically significant pattern. Having worked with adolescents who engage in NSSI behaviors for over six years this significant pattern of using first person plural was surprising, yet not unusual. One explanation for the frequent use of the first-person plural is the community's involvement in the social media realm. On Tumblr, many of the users appeared to express a sense of support from one another, whether that be emotional support and encouragement or support in continuing and improving their NSSI behaviors; in short, their discourse typically demonstrates that they experience a sense of belonging to something outside of themselves (Pennebaker, 2013). Another explanation for this pattern is the sense of numbness from their trauma that usually accompanies NSSI; Pennebaker (2013) in his book explains that usually after a trauma people often experience numbness and pain. His theory is that NSSI engaged individuals use NSSI to reduce and cope with the pain they experience in the moment and as a way to selfregulate; they intend to divert and avoid the pain. He states that it is common for people in this kind of pain to avoid using I words because the word I expresses vulnerability. Following Pennebaker's logic of avoiding emotional pain and vulnerability, it is unlikely that this population would choose to express its feelings and desires using first person singular pronouns. In addition to avoiding a sense of vulnerability, the use of we pronouns may also be the result of Tumblr's website protocol. Tumblr is not an anonymous posting website; because Tumblr accounts are linked to one's name and personal email, an individual is more likely to feel exposed. This relative ease of identification and exposure may be an additional reason for individuals engaged in NSSI to avoid using language that is too vulnerable. Of these three possible explanations, the most likely one is the sense of numbness from trauma. NSSI is typically associated with trauma symptoms which causes dissociation and distance from first 
person singular pronouns. The distancing nature of the first-person plural pronouns makes sense given the symptoms these individuals experience.

The third research question pertains to the psychological word use patterns in pro-NSSI blogs. The most common and statistically significant psychological pattern was the use of negative emotional language. Given the aforementioned literature, this use of negative emotion language would be expected in pro-NSSI blog posts. People who engage in NSSI are in extreme emotional pain; logically, it makes sense that the language they use is going to have a negative emotional tone. Several studies by Pennebaker (2013) suggest that people who use negative emotional language do not benefit from writing about their experiences (i.e. blogs), but instead remain stuck in the negativity, as though ruminating. This explanation suggests that people who post about their behavior in proNSSI blogs and social media continue to ruminate in their negative emotions and has the potential to also ruminate on other's behaviors as well, thus serving to trigger and continue the cycle of NSSI. An alternate explanation for the results obtained for the third research question is that these individuals are experiencing low self-esteem. Pennebaker, Mehl, and Niederhoffer (2003) found that there was a correlation between an individual with low scores in self-esteem assessments and the high use of negative emotion words. Of these two explanations, the former is most likely because while there is a correlation between negative emotion words and low self-esteem, it is a relatively small correlation. These individuals using NSSI and posting on blogs about their behavior are more likely to be ruminating on their negative circumstances and feel that need to connect those negative experiences with others.

The findings from this study reflects the work of many researchers who have explored how the language used by individuals provides insight into their mental health. This study discovered that the language used in pro-NSSI social media posts and blogs demonstrates a level of mental illness; it includes a high frequency of negative emotion language which signals rumination, the construction of a sense of community that may continue the cycle of NSSI behaviors and indicates that those who engage in NSSI may desperately be seeking coping skills and help. 
There are four limitations to this study that should be noted. Firstly, linguistic analysis is not perfect. A single word can have many meanings, so it is possible for a word to be categorized as an indicator of self-harm or negative emotional language when the author is using it in a different context; this could slightly skew the data. In order to control for this known limitation, the data was reviewed before it was inputted into the LIWC software in order to clarify any confusing word meanings. The second limitation to this study was that the study was limited to only English words due to the fact that the researcher only speaks English. This substantially limits the corpus because according to a 2013 study, approximately $21 \%$ of people in the United States speak a language other than English in their home (Camarota \& Zeigler, 2014). It is possible that some people who post on Tumblr blogs feel more comfortable writing in their native language. The third limitation is that the researcher was limited to using public Tumblr posts to create a corpus, because they chose not to use a private Tumblr account. Tumblr's settings allow their users to control their audience; an individual can post a blog and have the privacy settings set to be either fully public (so that it is visible to users with or without Tumblr accounts), public to members with Tumblr members only, visible to followers only, and private. This study limited itself to Tumblr blogs that were fully public, which did not require a log in, in an effort to respect the inherent privacy of a Tumblr blog post. The fourth limitation of this study is that its results might not be generalizable to the entire population of people who post on pro-NSSI social media and blog sites. Even though the effect size is relatively large for this study, inferences into the data should be done with care.

Two implications for practice and one implication for research emerged from this study. Many counselors who treat individuals who use NSSI are unaware of client online behaviors. This was evident in the Tumblr posts, where many individuals commented that their counselors are unaware that they are engaging in self-injury and that they are encouraged to self-injure by others online. Because counselors have the ethical responsibility to assess their clients' safety —including suicidal/ homicidal thoughts and self-injury behaviors, if an adolescent client is selfharming and the counselor has never conducted an assessment, the counselor is liable for not fulfilling their minimum ethical mandate if the client harms themselves seriously enough to be hospitalized. 
The first implication for practice is that it can inform the counselor about NSSI behaviors to ask patients about. It is necessary for counselors to know to ask their about NSSI behaviors; clients may not be comfortable bringing up NSSI behavior and may think that it is not appropriate to share in counseling - this is particularly true if the patient is experiencing any level of transference and wants to protect the counselor from their destructive patterns. In order to help counselors better fulfill their ethical mandate and to help them feel more comfortable bringing up NSSI, Cornell created a fact sheet for counselors. Included in the fact sheet were techniques for approaching NSSI, which discussed the importance of discussing online behavior. This is the first resource that encourages specific questions to clients regarding their online NSSI behavior (Ernhout, \& Whitlock, 2014).

The second practical implication revolves around treatment choices. Individuals who use NSSI to cope with extreme emotional distress are frequently isolated and are desperate to belong to community where they are not shamed. The language of shame can is clearly visible in the narratives of the blogs on Tumblr and in the results of this study, when analyzing the frequency of negative emotional tone.

NSSI behaviors, like cutting, are disturbing to any counselor and counselors, rightly, will choose an approach known to be effective is changing destructive behaviors. (i.e., Motivational Interviewing [MI] and Cognitive Behavioral Therapy [CBT]) (Washburn et al., 2012). Washburn et al., (2012) suggest that there is no effective treatment theory that was designed specifically for evidenced based treatment for NSSI. Therefore, they suggest that many counselors choose CBT as an easy to use standardized and evidenced based approach. This study, however, reveals a client profile that could help counselors understand individuals who practice NSSI behaviors; this profile suggests that individuals who practice NSSI have a harsh internal self-critic that is fueled the by the shame that surrounds NSSI behaviors. Therefore, it may be necessary to first help the clients "warm-up" to themselves before starting a more action oriented approach. 
One theoretical approach that is suggested by this new knowledge is Compassion Focused Therapy (CFT). While CFT shares many basic features with CBT, like exploring and examining triggers and how the brain reacts to said triggers, CFT takes the treatment a step beyond CBT by focusing on shame and self-compassion. In CFT, shame is recognized as a harmful emotion that keeps people in a state of negative emotions and rumination, and the practice of self-compassion can help a patient with severe mental illness to learn better ways to cope with negative emotional reactions (Gilbert, 2010). Neff (2009) adds that increasing selfcompassion reduces anxiety, a leading reason for NSSI behavior, and promotes better emotion regulation.

Another important implication for the research is a better understanding of the language of NSSI. Very few research studies have examined the specific language used by those who engage in NSSI behaviors. There is only a modicum of research using language analyzing software to understand the language characteristics of NSSI, which could have implications for improving treatment. This study adds to the existing research exploring language markers for mental health disorders by expanding the lens and giving voice to a misunderstood population of people. 


\section{References}

Aalai, A. (2018, June 8). The social contagion of suicide. Retrieved from https://www.psychologytoday.com/us/blog/the-firstimpression/201806/the-social-contagion-suicide

Adrian, M., Zeman, J., Erdley, C., Lisa, L., \& Sim, L. (2010). Emotional dysregulation and interpersonal difficulties as risk factors for Nonsuicidal Self-Injury in adolescent girls. Journal of Abnormal Child Psychology, 39, 389-400. http://dx.doi.org/10.1007/s10802010-9465-3

Allen, J. E. (2011, November 17). 1 in 12 Teens cut, deliberately hurt themselves. ABC News, ABC News Medical Unit. Retrieved from https://abcnews.go.com/Health/MindMoodNews/12-teens-cutharm-themsleves/story?id=14969232

Arensman, E., Larkin, C., Corcoran, P., Reulbach, U., \& Perry, I. J. (2013). Factors associated with self-cutting as a method of selfharm: Findings from the Irish National Registry of Deliberate SelfHarm. The European Journal of Public Health, 24(2), 292-297. https://dx.doi.org/10.1093/eurpub/ckt087

Camarota, S. A., \& Zeigler, K. (2014, October 3). One in five U.S. residents speaks foreign language at home, record 61.8 million. Retrieved from https://cis.org/One-Five-US-Residents-SpeaksForeign-Language-Home-Record-618-million

Chancellor, S., Lin, Z., Goodman, E. L., Zerwas, S., \& Choudhury, M. D. (2016). Quantifying and predicting mental illness severity in online pro-eating disorder communities. Proceedings of the 19th ACM Conference on Computer-Supported Cooperative Work \& Social Computing - CSCW 16, 1171-1184. http://dx.doi.org/10.1145/2818048.2819973

Choudhury, M. D., Counts, S., \& Horvitz, E. (2013). Major life changes and behavioral markers in social media. Proceedings of the 2013 Conference on Computer Supported Cooperative Work - CSCW 13. https://dx.doi.org/10.1145/2441776.2441937

Cressie, N., \& Read, T. R. (1989). Pearson's $\chi^{2}$ and the loglikelihood ratio statistic G2: a comparative review. International Statistical Review/Revue Internationale de Statistique, 57, 19-43. http://dx.doi.org/10.2307/1403582 
Dekmezian, G. (2016, September 23). Why do people blog? The benefits of blogging. Retrieved from https://www.huffingtonpost.com/garydekmezian/why-do-people-blog-the-be_b_8178624.html

Ernhout, C., \& Whitlock, J. (2014). Bringing up self-injury with your clients. The Fact Sheet Series, Cornell Research Program on SelfInjury and Recovery. Cornell University, Ithaca, NY.

Eveleth, R. (2013, July 22). What happened to 'self-harm blogs' after Tumblr banned them? Retrieved from https://www.smithsonianmag.com/smart-news/what-happened-toself-harm-blogs-after-tumblr-banned-them-15883320/

Favazza, A. R. (1998). The coming of age of self-mutilation. The Journal of Nervous \& Mental Disease, 186, 259-268. https://dx.doi.org/10.1097/00005053-199805000-00001

Gilbert, P. (2010). Compassion focused therapy. NY: Routledge.

Han, B., \& Baldwin, T. (2011). Lexical normalisation of short text messages: Makn sens a \#twitter. In Proceedings of the 49th Annual Meeting of the Association for Computational Linguistics: Human Language Technologies-Volume 1 (pp. 368-378). Stroudsburg PA: Association for Computational Linguistics. Retrieved from: https://dl.acm.org/citation.cfm?id=2002520

Hardie, A. (2014). Log Ratio - an informal introduction. Lancaster, UK: Centre for Corpus Approaches to Social Science. Retrieved from http://cass.lancs.ac.uk/log-ratio-an-informal-introduction/

Harris, I. M., \& Roberts, L. M. (2013). Exploring the use and effects of deliberate self-harm Websites: An Internet-Based Study. Journal of Medical Internet Research, 15. http://dx.doi.org/10.2196/jmir.2802

Jarvi, S., Jackson, B., Swenson, L., \& Crawford, H. (2013). The impact of social contagion on non-suicidal self-injury: A review of the literature. Archives of Suicide Research, 17, 1-19. http://dx.doi.org/10.1080/13811118.2013.748404

Lewis, S. P., \& Seko, Y. (2015). A double-edged sword: A review of benefits and risks of online non-suicidal self-injury Activities. Journal of Clinical Psychology, 72, 249-262. http://dx.doi.org/10.1002/jclp.22242

Li, F., \& Du, T. C. (2014). Listen to me - Evaluating the influence of micro-blogs. Decision Support Systems, 62, 119-130. http://dx.doi.org/10.1016/j.dss.2014.03.008 
Mars, B., Heron, J., Biddle, L., Donovan, J. L., Holley, R., Piper, M., . . . Gunnell, D. (2015). Exposure to, and searching for, information about suicide and self-harm on the Internet: Prevalence and predictors in a population based cohort of young adults. Journal of Affective Disorders, 185, 239-245.

http://dx.doi.org/10.1016/j.jad.2015.06.001

McGlashan, M. (Ed.). (2018). Corpus: Some key terms. CASS: Briefings. Retrieved from http://cass.lancs.ac.uk/wpcontent/uploads/2013/12/CASS-Gloss-final1.pdf

Moreno, M. A., Ton, A., Selkie, E., \& Evans, Y. (2016). Secret Society 123: understanding the language of self-harm on Instagram. Journal of Adolescent Health, 58, 78-84.

https://doi.org/10.1016/j.jadohealth.2015.09.015

Mueller, A. S. (2017). Does the media matter to suicide?: Examining the social dynamics surrounding media reporting on suicide in a suicide-prone community. Social Science \& Medicine, 180, 152-159. http://dx.doi.org/10.1016/j.socscimed.2017.03.019

Neff, K. D. (2009). The role of self-compassion in development: A healthier way to relate to oneself. Human Development, 52, 211214. http://dx.doi.org/10.1159/000215071

O'Reilly, M., Dogra, N., Whiteman, N., Hughes, J., Eruyar, S., \& Reilly, P. (2018). Is social media bad for mental health and wellbeing? Exploring the perspectives of adolescents. Clinical Child Psychology and Psychiatry, 23, 601-613. http://dx.doi.org/10.1177/1359104518775154

Pennebaker, J. W. (2013). The secret life of pronouns: What our words say about us. NY: Bloomsbury Press.

Pennebaker, J.W., Boyd, R.L., Jordan, K., \& Blackburn, K. (2015). The development and psychometric properties of LIWC2015. Austin, TX: University of Texas at Austin. http://dx.doi.org/10.15781/T29G6Z

Pennebaker, J.W., Chung, C.K., Ireland, M., Gonzales, A., \& Booth, R.J., (2007). The development and psychometric properties of LIWC2007. Austin, TX: University of Texas at Austin.

Rayson, P., \& Garside, R. (2000). Comparing corpora using frequency profiling. In Proceedings of the workshop on comparing corporaVolume 9 (pp. 1-6). Stroudsburg, PA: Association for 
Computational Linguistics.

http://dx.doi.org/10.3115/1117729.1117730

Healthyplace.com. (2016). Self-injurious behavior, self-injury treatment.

San Antonio, TX: Author. Retrieved from

https://www.healthyplace.com/abuse/articles/self-injurious-

behavior-self-injury-treatment

Skegg, K. (2005). Self-harm. Lancet, 366, 1471-1483.

https://doi.org/10.1016/S0140-6736(05)67600-3

Smith, A., \& Anderson, M. (2018, September 19). Social Media Use 2018:

Demographics and Statistics. Washington, DC: Pew Research

Center. Retrieved from

http://www.pewinternet.org/2018/03/01/social-media-use-in-2018/

Tausczik, Y. R., \& Pennebaker, J. W. (2009). The psychological meaning of words: LIWC and computerized text analysis methods. Journal of Language and Social Psychology, 29, 24-54.

http://dx.doi.org/10.1177/0261927x09351676

Washburn, J. J., Richardt, S. L., Styer, D. M., Gebhardt, M., Juzwin, K. R., Yourek, A., \& Aldridge, D. (2012). Psychotherapeutic approaches to non-suicidal self-injury in adolescents. Child and Adolescents Psychiatry and Mental Health, 6(14). https://doi.org/10.1186/1753-2000-6-14

Weisser, M. (2016). Practical corpus linguistics: An introduction to corpus-based language analysis. NY: John Wiley \& Sons.

Williams, J. M. G., \& Pollock, L. R. (2000). The psychology of suicidal behaviour. In K. Hawton and K. van Heeringen K (Eds.), The international handbook of suicide and attempted suicide (pp. 7993). Chichester, UK: John Wiley \& Sons.

https://doi.org/10.1002/9780470698976.ch5 
Table 1

Item Word Counts

\begin{tabular}{|c|c|c|c|c|c|c|c|}
\hline Word/Stem & Methods & $\begin{array}{l}\text { Cutting } \\
\text { Terms }\end{array}$ & $\begin{array}{l}\text { NSSI } \\
\text { Terms }\end{array}$ & $\begin{array}{c}\text { Instru- } \\
\text { ments } \\
\text { Used }\end{array}$ & $\begin{array}{c}\text { Reasons } \\
\text { for } \\
\text { NSSI }\end{array}$ & $\begin{array}{c}\text { Hidden } \\
\text { Hashtag } \\
\text { Terms }\end{array}$ & $\begin{array}{c}\text { Word } \\
\text { Ct. }\end{array}$ \\
\hline Cut & & $\mathrm{X}$ & & & & & 585 \\
\hline Cutt* & & $\mathrm{X}$ & & & & & 543 \\
\hline Cutting & & $\mathrm{X}$ & & & & & 146 \\
\hline Anxiety & & & & & $\mathrm{X}$ & & 62 \\
\hline Control & & & & & $\mathrm{X}$ & & 98 \\
\hline Blade & & & & $\mathrm{X}$ & & & 119 \\
\hline Burning & $\mathrm{X}$ & & $\mathrm{X}$ & & & & 96 \\
\hline Anger & & & & & $\mathrm{X}$ & & 110 \\
\hline Picking & $\mathrm{X}$ & & $\mathrm{X}$ & & & & 93 \\
\hline Attention & & & & & $\mathrm{X}$ & & 69 \\
\hline Hitting & $\mathrm{X}$ & & $\mathrm{X}$ & & & & 85 \\
\hline Addiction & & & & & $\mathrm{X}$ & & 30 \\
\hline Bite & $\mathrm{X}$ & & & & & & 27 \\
\hline Fingernail & & & & $\mathrm{X}$ & & & 8 \\
\hline Biting & & & $\mathrm{X}$ & & & & 15 \\
\hline Empty & & & & & $\mathrm{X}$ & & 68 \\
\hline Eraser & & & & $\mathrm{X}$ & & & 362 \\
\hline Mauled & & & & & & $\mathrm{X}$ & 0 \\
\hline Bleach & & & & $\mathrm{X}$ & & & 4 \\
\hline Erasing & $\mathrm{X}$ & & $\mathrm{X}$ & & & & 106 \\
\hline ehtilb & & & & & & $\mathrm{X}$ & 0 \\
\hline Laxatives & & & & $\mathrm{X}$ & & & 0 \\
\hline mysecretfamily & & & & & & $\mathrm{X}$ & 0 \\
\hline secretsociety_123 & & & & & & $\mathrm{X}$ & 0 \\
\hline selfharmmmm & & & & & & $\mathrm{X}$ & 0 \\
\hline selfinjuryyy & & & & & & $\mathrm{X}$ & 0 \\
\hline
\end{tabular}


Table 2

Results for Linguistic and Psychological Processes

\begin{tabular}{|c|c|c|c|c|c|c|}
\hline Category & Process Type & $\begin{array}{c}\text { Tumblr } \\
\text { Word } \\
\text { Count }\end{array}$ & $\begin{array}{c}\text { Blog } \\
\text { Norm } \\
\text { Word } \\
\text { Count }\end{array}$ & $\begin{array}{l}\text { Over/ } \\
\text { Under } \\
\text { Use }\end{array}$ & $\begin{array}{c}\text { Log } \\
\text { Likeli- } \\
\text { hood }\end{array}$ & $\begin{array}{c}\text { Log } \\
\text { Ratio }\end{array}$ \\
\hline 1st Person Singular & Linguistic & 21772.47 & 200.72 & + & 0.29 & 0.05 \\
\hline Negative Emotion & Psychological & 9747.37 & 66.05 & + & $8.80^{* *}$ & 0.50 \\
\hline 1st Person Plural & Linguistic & 1205.86 & 29.18 & - & $18.59 * *$ & -1.34 \\
\hline Anxiety & Psychological & 1373.34 & 8.66 & + & 1.73 & 0.60 \\
\hline Sad & Psychological & 2244.24 & 14.11 & + & 2.86 & 0.61 \\
\hline Risk & Psychological & 2009.77 & 14.75 & + & 1.13 & 0.38 \\
\hline Anger & Psychological & 2847.17 & 21.80 & + & 1.16 & 0.32 \\
\hline $\begin{array}{l}\text { 3rd Person Plural } \\
\text { 3rd Person }\end{array}$ & Linguistic & 2344.73 & 21.80 & + & 0.02 & 0.04 \\
\hline Singular & Linguistic & 5359.38 & 48.10 & + & 0.20 & 0.09 \\
\hline
\end{tabular}

